\title{
Pedro Damião e A dialéticA ${ }^{1,2}$ \\ Lessandro Regiani Costa (USP) ${ }^{3}$ \\ lessandrorcosta@gmail.com
}

Resumo: Pedro Damião (1007-1072) normalmente é descrito no interior da história da filosofia como uma espécie de inimigo da dialética, o exemplo mais acabado do anti-intelectual medieval. Boa parte de sua fama é resultado de um excerto de sua obra De divina omnipotentia em que ele parece defender que Deus poderia ferir o princípio de não-contradição. Com este trabalho, pretendemos mostrar que Damião não ataca a validade do princípio de nãocontradição, assim como não chega a elaborar uma crítica geral aos princípios dialéticos, mas também não parece um entusiasta da mesma, sobretudo em questões de fé. De modo que ainda que não seja justo caracterizá-lo como um ferrenho anti-intelectual, é preciso considerar seu pouco entusiasmo em relação à aplicação da dialética em teologia.

Palavras-chave: Pedro Damião; dialética; princípio de não-contradição.

Se considerarmos o que nos dizem os historiadores da filosofia sobre a pessoa de Pedro Damião (1007-1072), seremos obrigados a concluir que ele tendia ao caricatural. Desde o início caracterizado como "o tipo mais acabado do antiintelectualismo medieval” (GONSETTE 1956, 5), aquele que "não estava satisfeito em simplesmente criticar o uso deslocado e equivocado da dialética na teologia; [que] visava negar a possibilidade de ciência independente da teologia”

\footnotetext{
${ }^{1}$ Recebido em: 09-10-2015/Aceito em: 16-11-2015/Publicado on-line: 06-03-2016.

${ }^{2}$ Este artigo é fruto de parte do trabalho desenvolvido no doutorado, que contou com o apoio financeiro da CAPES e da FAPESP.

${ }^{3}$ Lessandro Regiani Costa é Doutor em filosofia pela USP, São Paulo, SP, Brasil.
} 
(HOLOPAINEN 1996, 8). Em suma, o retrato de alguém que odiava a filosofia (BOEHNER, GILSON 2000, 251).

Por volta do ano de 1064, Damião fez uma visita ao mosteiro beneditino de Monte Cassino. Durante uma das refeições, foi lido um texto de Jerônimo que dizia que apesar de Deus ser capaz de tudo (omnia possit), ele não poderia restaurar a virgindade de uma mulher desvirginada. Diante disso, Pedro Damião confessa seu desagrado em se atribuir a Deus uma impossibilidade. O abade Didier, por outro lado, se mostra disposto a defender a posição de Jerônimo Deus não pode fazê-lo porque não deseja fazê-lo. Ao que Damião contra-argumenta: entre as coisas que Deus atualmente não deseja fazer, há muitas que ele poderia fazer. Deus, por ser onipotente, certamente poderia restaurar a virgindade (PEDRO DAMIÃO 1994, 596C-597B). Dessa maneira, assim como o Monologion de Anselmo de Cantuária, o De divina omnipotentia ${ }^{4}$ surge como uma resposta ao pedido dos monges que desejavam conhecer um pouco melhor a posição de Damião sobre determinada questão.

O que intriga a todos em sua asserção é que se Deus é onipotente em todas as coisas, ele poderia fazer com que aquilo que foi não tenha sido? Deus poderia, por exemplo, fazer com que Roma não tenha sido fundada? Ao que tudo indica (620D), no transcorrer da disputa Damião não conseguiu responder positivamente à questão. Para resolver isso, e esclarecer seu pensamento ao abade Didier e toda sua comunidade, ele escreve a carta conhecida como De divina omnipotentia. Desta, um pequeno trecho se destaca no

\footnotetext{
${ }^{4}$ Inicialmente, De divina omnipotentia foi datado em 1067, posteriormente Reindel, em sua edição das cartas de Pedro Damião, datou a carta ( $\left.n^{\circ} 119\right)$ em 1065. Cf. CANTIN (PEDRO DAMIÃO 2006, 31-32); RESNICK $(1992,20)$.
} 
interior da história da filosofia - 612A-B.

Com efeito, o que foi não pode verdadeiramente ser dito que não foi, e, inversamente, o que não foi não é correto dizer que foi. Pois os contrários são incompatíveis em um e o mesmo sujeito. Esta impossibilidade, tem-se sem dúvida razão de afirmá-la quando é referida às limitações da natureza, mas não deve ser aplicada à majestade divina. Pois aquele que deu nascimento à natureza facilmente remove a necessidade da natureza quando ele quer. ${ }^{5}$

O responsável por "descobrir" essa passagem no início do século XX foi Endres (1906). Nesse pequeno trecho Damião parece dizer que Deus pode desfazer algo já feito mesmo que isso implique a violação do princípio de nãocontradição. De modo que o princípio de não-contradição pertenceria ao domínio das leis da natureza, esfera do contingente. Isso seria o bastante para levar a crítica de Pedro Damião à dialética a outro nível. Ao que parece, ele pretendia negar a possibilidade de conhecimento independente da teologia.

Desse modo, analisaremos o De divina omnipotentia considerando as passagens mais relevantes no que se refere à aplicação da dialética em teologia. O que nos levará a considerar três pontos: primeiramente, a noção de onipotência de Deus; em segundo lugar, a capacidade divina de fazer coisas que alteram a ordem comum da natureza; e, por fim, a posição de Pedro Damião a respeito das contradições que a habilidade divina pode gerar.

\footnotetext{
5 "Nam quod fuit non potest uere dici quia non fuit, et e diuerso quod non fuit non recte dicitur quia fuit. Quae enim contraria sunt in uno eodemque subiecto congruere nequeunt. Haec porro inpossibilitas recte quidem dicitur si ad naturae referatur inopiam; absit autem ut ad maiestatem sit applicanda diuinam. Qui enim naturae dedit originem, facile, cum uult, naturae tollit necessitatem". De divina omnipotentia, 612 A-B.
} 


\section{ONIPOTÊNCIA}

O principal objetivo de Pedro Damião em De divina omnipotentia é defender a doutrina da onipotência de Deus. Em poucas palavras, ele entende que onipotente é aquele que tem o poder de fazer tudo que desejar, ou o poder de fazer qualquer coisa que seja um bem.

Em sua visão, as coisas do mundo podem ser divididas em duas classes: as boas (bona) e as más (mala) (608B-610D). Sua análise não tem a pretensão de fornecer uma lista exaustiva sobre os ítens de cada classe, mas ela parte de um certo consenso acerca do que seja bom e mau. Nesse caso, a perda da virgindade seria uma coisa má, e sua restauração um bem. Assim como um homem reto é bom, e um pecador é mau. O que caracteriza uma coisa boa é que ela é (esse) e que ela é algo (aliquid). As coisas boas são feitas por Deus, e, consequentemente, desejadas por ele. "A vontade de Deus é a causa eficiente do ser das coisas" (HOLOPAINEN 1996, 13). Portanto, aquilo que Deus não deseja que seja, não será. Às coisas boas, por serem desejadas por Deus, não resta outra opção que não o ser (608D609B).

Damião não deixa dúvida quanto à liberdade de Deus em sua atividade criadora. Antes de mais nada, Deus não é levado a criar por qualquer tipo de necessidade; o criar é fruto unicamente de sua bondade. Do mesmo modo, a criação em nada altera sua perfeição. Ele escolhe e ordena o que fará parte da criação segundo sua livre escolha, o que não restringe sua ação. Como autor das leis da natureza, mesmo a necessidade da natureza se submete à sua vontade (612C-D). Há apenas um "limite" à liberdade divina. Deus escolhe livremente o que será criado, mas sua escolha se dá 
em meio às coisas boas. Se algo é mau, Deus não pode criálo, pois ele não pode desejar algo mau. Visto que Deus é bondade, não pode desejar algo mau, e, portanto, não pode criar algo mau. Tampouco é constrangido a criar tudo aquilo que é bom. ${ }^{6}$

De acordo com o que diz Damião sobre a discussão em Monte Cassino, o abade Didier pretendia fazer coro à tradição que entendia a onipotência como o poder para fazer o que se deseja (potest facere quod vult) (COURTENAY 1985). No entanto, se Deus pode fazer somente o que ele deseja, e ele só deseja aquilo que efetivamente fez, segue-se que ele não pode fazer aquilo que, de fato, não fez. Mas até mesmo o homem, aponta Damião, é capaz de fazer muitas coisas que ele efetivamente não faz (596D-597B). Para ele, a onipotência divina deve ser entendida em termos do que Deus pode querer (potest velle), como a capacidade divina de criar qualquer coisa que seja boa (600A-B). Daí sua definição de onipotência (omnipotentia) como a capacidade de tudo (possit omnia), em que "tudo" se refere às coisas boas, e inclui todas as coisas que poderiam ser algo (esse) se Deus as escolhesse (610C-D).

\section{MilaGRES}

Nesse momento, já temos os elementos da resposta geral de Pedro Damião ao problema da restauração da virgindade.

\footnotetext{
${ }^{6} \mathrm{O}$ bem não se restringe apenas ao melhor, sendo possível que alternativas incompatíveis sejam igualmente boas. Nesse sentido, a imortalidade é sempre algo bom para os homens; porém, em nossa situação atual, a mortalidade também é um bem (599C-D). De modo semelhante, como sustenta Resnick (1992, 72-76/83), a palavra "mal" também parece ter um duplo significado. Primeiramente, "there are evils which are defined relative to the present order, as for example the conferral of immortality or the restoration of virginity". Em segundo lugar, "evil is defined in another sense as that which is without the conditions of being, as nothingness, which is separate from God". No primeiro caso, um mal pode ser tornar algo bom.
} 
Deus, sendo onipotente, pode querer e criar tudo que seja bom. Visto que a restauração da virgindade é um bem, Deus pode fazê-lo (600B). Damião expandirá sua resposta ao explicar que se pode entender a restauração da virgindade como a plenitude de méritos (iuxta meritorum plenitudinem) ou a integridade da carne (iuxta carnis integritatem). Enfim, Damião finaliza a questão da virgindade declarando que Deus pode restaurar a virgindade a uma mulher, não importando quantos maridos tenha tido, e também pode restituir o signo da virgindade a seu corpo (600C-601B). Pedro Damião trata da questão sem nem ao menos mencionar o tema da mudança do passado. Sob todos os aspectos a restauração da virgindade se dá em algum momento do presente.

Dado que a restauração da virgindade não é algo corriqueiro, deveríamos entender se tratar de um milagre?

É por esse caminho que Damião segue ao comparar a restauração da virgindade ao nascimento virginal. Segundo ele, a restauração seria um milagre menor que o nascimento virginal, pois enquanto este seria como atravessar uma porta sem abri-la aquele seria como fechar uma porta depois de aberta (611B-C). Ele também compara a restauração e o nascimento virginal com a vida eterna de Enoque (Eclesiástico 44:16; Hebreus 11:5) e a ressurreição de Lázaro (João 11). O que há de comum em todos esses casos é a restauração de algo a seu estado original. Assim como a restauração da virgindade não afeta o passado de nenhum modo, a ressurreição de Lázaro também não muda o fato de que ele tenha morrido. Desse modo, como nota Holopainen (1996, 17), pode-se dizer que Damião entende a restauração da virgindade como um milagre "ordinário", comparável a outros descritos na Bíblia. Discutir sobre a virgindade restaurada é 
discutir sobre o poder divino de produzir milagres.

Nesse sentido, as leis da natureza podem se apresentar como um motivo para que se negue a possibilidade de tais milagres. Pois segundo a ordem natural, parece ser impossível reparar a perda da integridade física. Ao menos é o que alguns silogismos que Damião discute sugerem. "Se a madeira queima, é consumida; a madeira queima; logo, é consumida". Por outro lado, a sarça ardente vista por Moisés não queimou (Êxodo 3:2). Na mesma direção, "se um ramo de árvore é cortado, não produz fruto; o ramo é cortado; logo, não produz fruto". O ramo de Arão, porém, florescia (Números 17:8). Damião não parece temer os dialéticos, na verdade ele chega a provocá-los - que se valham do silogismo hipotético! "Se uma mulher pariu, se deitou com um homem; ela pariu; logo, se deitou com um homem" (610C-611B).

Essa passagem é uma das duas presentes em De divina omnipotentia em que Pedro Damião fala explicitamente sobre dialética e dialéticos. Ele se vale inclusive de terminologia técnica (proponere, assumere e concludere) (BOÉCIO 1969, 210, 23-27). Apesar disso, não é tão fácil saber a importância desse texto em relação à crítica de Damião à dialética, pois o silogismo hipotético sobre dar à luz e se deitar com um homem está presente em muitas obras que serviram de base para os dialéticos e retóricos do início da Idade Média.

No De inventione de Cícero, por exemplo, o silogismo é mencionado como um caso de argumento necessário (CÍCERO 1908, 145, 3-10). Boécio fará uso do mesmo exemplo em sua discussão sobre os tópicos antecedentes e consequentes, sustentando que a validade de um argumento baseado em um desses tópicos depende de uma 
proposição condicional (BOÉCIO 1969, 54, 15-55, 18). Em De hypotheticis syllogismis ele utiliza a inferência sobre dar à luz e se deitar com um homem para exemplificar a natureza de uma proposição condicional (BOÉCIO 1969, 210, 1-7). Para Boécio, proposições condicionais verdadeiras são necessárias, assim como a verdade de algumas é baseada em conexão causal entre o antecedente e o consequente (BOÉCIO 1969, 250, 18-29; 218, 52-220, 76). Ao que parece, Boécio não vê problema algum entre o silogismo de dar à luz e a doutrina cristã.

Mario Vitorino, por outro lado, segue um caminho diferente. Na sua visão, não há, a rigor, nenhum argumento estritamente necessário (MÁRIO VITORINO 1833, 89, 2890, 6). Visto que seu comentário ao De inventione era utilizado como uma importante fonte nos estudos de retórica à época de Damião (PEDRO DAMIÃO 2006, 210; RESNICK 1992, 56), é provável que Damião soubesse que Cícero introduzira o silogismo sobre dar à luz como exemplo de um argumento necessário. Assim como devia saber também que mesmo entre os dialéticos havia incerteza quanto à natureza dessa inferência. De todo modo, o interesse dele parece estar no "estatuto dessas regularidades na natureza que são assumidas para garantir a necessidade de silogismos do tipo que ele citou" (HOLOPAINEN 1996, 21). Entende-se assim a razão dele, em seguida, passar a tratar da relação entre o poder de Deus e as leis da natureza.

A ideia principal é que Deus tem poder soberano sobre a natureza. Não se deve pensar que as leis da natureza determinam o que é possível, pois Deus pode querer e criar qualquer coisa que seja um bem. Como autor da natureza ele pode mudar suas leis de acordo com sua livre escolha, cabendo à natureza obedecer à vontade de seu criador 
(612B-D). Como evidência disso, Damião enumera uma série de eventos miraculosos que contrariam o curso normal da natureza, que compreendem milagres bíblicos e fenômenos atestados por fontes seculares, como a salamandra que vive no fogo (612D) e o funcionamento do ímã (613C). Por fim, ele encerra a discussão reafirmando a habilidade de Deus para restaurar a virgindade por meio de um milagre.

\section{O PODER DIVINO E A NECESSIDADE}

A discussão que teve início com a questão da restauração da virgindade adquire um aspecto mais amplo. Trata-se agora de analisar a habilidade de Deus desfazer o que já foi feito. O ponto de partida de Pedro Damião é a visão bíblica de que "Deus faz ser o que não era, e não destrói o que era; cria o futuro, não abole o passado". Mesmo quando algo é destruído para produzir alguma coisa melhor, como no caso do dilúvio, apenas o presente e futuro são suprimidos, nunca o passado (601D-602A). Além disso, é preciso ter em mente que a destruição de algo mau é um caso especial, pois, a rigor, ele nem ao menos tem ser (602A-C).

Damião antecipa algo de sua discussão acerca da segunda grande questão do De divina omnipotentia, a mudança do passado. Todavia, antes de passar propriamente a ela, ele se deterá no background teórico de seus oponentes (602D604B), relacionando a questão da habilidade divina para modificar o passado com uma controvérsia dialética sobre a consequência da necessidade ou impossibilidade (consequentias necessitatis uel inpossibilitatis).

Sua posição sobre aqueles que fazem da habilidade divina para modificar o passado objeto de discussão é clara homens vãos (vani homines) que não entendem a importân- 
cia de seus questionamentos. Perguntam se Deus pode modificar aquilo já feito, mas não se dão conta de que esse tipo de impossibilidade não se aplica apenas ao passado. "Afinal, tudo o que é agora, durante o tempo que é, sem dúvida é necessário que seja. Com efeito, enquanto uma coisa é, é impossível que não seja. Da mesma forma, o que é futuro, é impossível que deixe de ser futuro" (602D). Assim como em relação ao futuro, há uma série de coisas que podem indiferentemente ocorrer ou não, como encontrar um amigo ou não encontrar um amigo. Os "sábios deste século" (saeculi sapientes) chamam as eventualidades desse tipo de "um-ououtro" (utrumlibet). Essas variações, no entanto, seguem a variabilidade natural das coisas, não o encadeamento lógico dos enunciados. Considerando a consequência das proposições (consequentia dictionum), se vai chover, então necessariamente choverá, é impossível que não chova. Desse modo, o mesmo tipo de consequência que vale para o passado, valerá para o presente e o futuro (602D-603B).

Dessa maneira, quando se aplica as regras da dialética para se questionar o poder divino de modificar o passado, a ação de Deus é restringida não apenas em relação ao passado, mas também em relação ao presente e ao futuro. $\mathrm{O}$ que os dialéticos fazem é opor as necessidades presentes nessas conclusões ao poder de Deus, "aplicam impudentemente a Deus o que pertence somente à arte de discutir" (603B). Prendem-se às consequências das palavras exteriores, e esquecem o caminho da verdade (603C). ${ }^{7}$ Afinal de contas,

\footnotetext{
${ }^{7}$ Em De incarnatione Verbi (1984, I, 9, 20-10, 13), Anselmo diz algo parecido sobre os "heréticos da dialética", presos ao sopro da voz. "Cumque omnes ut cautissime ad sacrae paginae quaestiones accedant, sint commonendi: illi unque nostri temporis dialectici, immo dialecticae haeretici, qui non nisi flatum uocis putant uniuersales esse substantial, et qui colorem non aliud queunt intelligere quam corpus, nec sapientiam hominis aliud quam animam, prorsus a spiritualium quaestionum disputatione sunt exsufflandi. In eorum quippe animabus ratio, quae et princeps et Cont.
} 
quem não vê que se "essas argumentações são admitidas, tal qual são formadas pela ordem lógica das palavras, demonstrar-se-á que o poder divino é impotente em cada um dos momentos do tempo?" (603D)

Os antigos mestres das artes liberais, lembra Damião, discutiram a questão à exaustão, mas nenhum deles chegou ao ponto de acusar Deus de impotência (inpossibilitas). Sobretudo quando cristãos, trataram do problema da consequência da necessidade e impossibilidade (consequentia necessitatis uel inpossibilitatis) dentro dos limites da dialética, evitando fazer qualquer conexão com Deus (604A). Para Damião, não se trata de uma discussão sobre o poder de Deus, mas de uma questão que pertence ao domínio da dialética. Não diz respeito à realidade das coisas, "mas às regras e ordem da discussão e o encadeamento das palavras". Portanto, "esta questão concerne muito mais ao encadeamento das palavras que ao mistério da Igreja" (haec quaestio potius ad consequentiam uerborum quam ad Ecclesiae pertineat sacramentum). Nesse caso, Damião pode deixar a questão para os sábios deste século, contentando-se em apresentar uma breve defesa da fé. ${ }^{8}$

iudex debet omnium esse quae sunt in homine, sic est in imaginationibus corporalibus obuoluta, ut ex eis se non possit euoluere, nec ab ipsis ea quae ipsa sola et pura contemplari debet, ualeat discernere. Qui enim nondum intelligit quomodo plures homines in specie sint unus homo: qualiter in illa secretissima et altissima natura comprehendet quamodo plures personae, quarum singula quaeque perfectus est deus, sint unus deus? Et cuius mens obscura est ad diiudicandum inter equum suum et colorem eius: qualiter discernet inter unum deum et plures relationes eius? Denique qui non potest intelligere aliquid esse hominem nisi indiuiduum, nullatenus intelliget hominem nisi humanam personam. Omnis enim indiuiduus homo est persona. Quomodo ergo iste intelliget hominem assumptum esse a uerbo, non personam, id est naturam aliam, non aliam personam assumptam esse?".

${ }^{8}$ Estaria Damião defendendo a ideia de que a dialética é uma arte puramente verbal? É o que pensam André Cantin (PEDRO DAMIÃO 2006, 188-191/220-221) e Gonsette (1956, 46-48). Entretanto, como nota Holopainen, Damião está discutindo aqui a natureza de uma questão específica da dialética, e não a natureza geral dessa arte. Além disso, em determinado momento da obra (615A-B) o próprio Damião faz referência à natureza das coisas. 
A questão sobre a consequência da necessidade e impossibilidade se inicia com a discussão de Aristóteles sobre as proposições futuras contingentes no nono capítulo do De interpretatione (BARBOSA FILHO 2003; 2005). A posição de Aristóteles, de acordo com Boécio, seria a de que se uma proposição tem um valor de verdade definido, então o evento a que se refere acontecerá necessariamente. $\mathrm{O}$ que não impediria, por sua vez, a existência de eventos genuinamente contingentes (utrumlibet). Visto que tais eventos não acontecem por necessidade, as proposições que se referem a eles não têm um valor de verdade definido, ainda são verdadeiras ou falsas, mas seu valor de verdade é indefinido (BOÉCIO 1880, I, 105.28-106.14; I, 111, 17-28).

Uma fonte relevante a respeito do status quaestionis à época de Pedro Damião é Anselmo de Cantuária, especialmente sua discussão em Cur deus homo sobre os dois tipos de necessidade (1984, XVII, 122-126). Ele estabelece uma distinção entre necessidade precedente (necessitas praecedens) e necessidade subsequente (necessitas sequens). A necessidade precedente é a causa do estado atual de uma coisa, uma espécie de necessidade eficiente, assim como dizemos que é necessário que o céu se mova, porque de fato se move. A necessidade subsequente, por outro lado, não é causa eficiente de nada, ela é causada pelo estado atual de uma coisa. Assim como dizemos: porque Boso está falando, ele necessariamente está falando. Não há nada nessa proposição que indique que Boso é compelido a falar, na verdade, o que se diz é que nada pode fazer com que não esteja falando enquanto ele estiver falando. Trata-se de uma necessidade que se aplica a todos os tempos, pois aquilo que foi, necessariamente terá sido; o que é, necessariamente é; e, por fim, aquilo que será, necessariamente será. Segundo Anselmo, é 
a necessidade subsequente que, na discussão de Aristóteles, parece destruir a indeterminação do utrumlibet (1984, XVII, $125,8-22)$. Visto que apenas a necessidade precedente pode, de modo eficiente, infringir a liberdade de um agente, apenas ela é genuinamente uma necessidade. Ao menos num primeiro momento, Anselmo parece entender que o problema das proposições contingentes reside na dificuldade em se separar os dois tipos de necessidade.

Sob esse aspecto, o texto de Damião (602D-604B) ganha uma nova perspectiva. Ao rejeitar que a necessidade que se segue de uma proposição verdadeira qualquer possa afetar o poder de Deus, ele parece ter em mente uma distinção semelhante àquela de Anselmo. Certamente há um tipo de necessidade que diminui a liberdade dos agentes, impingindo-lhes impotência. Esse parece ser o caso das proposições condicionais que descrevem o curso ordinário da natureza, daí o esforço de Damião em demonstrar que Deus tem poder sobre as leis da natureza. A necessidade que se segue de uma proposição verdadeira qualquer, por outro lado, não representa risco ao poder divino, haja vista a existência dos eventos futuros contingentes (615A-B).

\section{O PRINCÍPIO DE NÃO-CONTRADIÇÃO E A ONIPOTÊNCIA DIVINA}

De todo modo, mais do que resolver a questão dos futuros contingentes, o que nos interessa aqui é a maneira de Damião lidar com a dialética em um contexto teológico. Ele comenta sobre qual deve ser a atitude não só da dialética, mas de toda ciência humana quando voltada a questões teológicas.

Mas se acontece que a ciência humana seja empregada ao exame da 
palavra sagrada, ela não deve tomar para si o magistério com presunção, mas, como uma escrava, obedecer sua senhora com a submissão daquele que serve, com medo de precedê-la ela não se desvia, e que ao seguir os encadeamentos das palavras exteriores ela não perca a luz do poder interior e o reto caminho da verdade. ${ }^{9}$

"Ancilla" é a palavra que define o papel da dialética em relação à Palavra sagrada. Ela deve reconhecer seu papel secundário e não pretender usurpar a posição de sua domina. Como observa Holopainen (1996, 30), Damião parece não achar "necessário apresentar nesse contexto qualquer crítica em relação à validade dos princípios da dialética, pois ele sustenta que as dificuldades que ele descreveu surgem de um entendimento deficiente dos problemas dialéticos relevantes".

Buscando clarificar a relação entre o poder divino e a consequência da necessidade, Damião se dedica à análise da eternidade de Deus e sua relação com a criação (604C608A). Sua apresentação se dedica a mostrar que Deus possui poder soberano sobre toda a história da criação, de modo que para ele não há passado ou futuro, mas um eterno presente. Nesse dia eterno, a Criação e o Julgamento permanecem imutáveis (607A-B). Inicialmente, ele se volta

\footnotetext{
9 "Videat ergo inperite sapientium ut uana quaerentium caeca temeritas, quia si haec quae ad artem pertinent disserendi ad Deum procaciter referant, iam non tantum in praeteritis, sed et in praesentibus ac futuris, eum inpotentem penitus et inualidum reddant. Qui nimirum, quia necdum didicerunt elementa uerborum, per obscuras argumentorum suorum caligines amittunt clarae fidei fundamentum, et ignorantes adhuc quod a pueris tractatur in scolis, querelae suae calimnias diuinis ingerunt sacramentis, et quia inter rudimenta discentium uel artis humanae nullam apprehendere peritiam, curiositatis suae nubilo pertubant puritatis ecclesiasticae disciplinam. Haec plane quae ex dialecticorum uel rhetorum prodeunt argumentis non facile diuinae uirtutis sunt aptanda mysteriis, et quae ad hoc inuenta sunt ut in syllogismorum instrumenta proficiant uel clausulas dictionum, absit ut sacris se legibus pertinaciter inferant et diuinae uirtuti conclusionis suae necessitates opponant. Quae tamen artis humanae peritia, si quando tractandis sacris eloquiis adhibetur, non debet ius magisterii sibimet arroganter arripere, sed uelut ancilla dominae quodam famulatus obsequio subseruire, ne, si praecedit, oberret, et dum exteriorum uerborum sequitur consequentias, intimae uirtutis lumen et rectum ueritatis tramitem perdat". De divina omnipotentia, 603B-D.
} 
à análise da eternidade de Deus para mostrar que quando se trata do poder divino, aquilo que vale para o presente também é válido para o passado e o futuro. $\mathrm{O}$ que lhe interessa agora é responder àqueles que questionam se Deus poderia criar algo contraditório (608A-B). Por aquilo que já vimos, podemos antever sua resposta. Afinal de contas, tudo que Deus cria é bom, e, portanto, algo (aliquid), o que não seria o caso de algo contraditório (608B-C).

Portanto, quando tu pedes que uma só e a mesma coisa tenha sido e não sido, seja e não seja, venha a ser e não venha a ser, tu te esforças de fato em confundir todas as coisas passadas ou futuras, e de demonstrar que elas permanecem suspensas entre o ser e o não ser, o que a natureza exclui seguramente, pois nada pode ao mesmo tempo ser e não ser; mas o que não está na natureza, certamente é nada. Portanto, tu pedes a Deus, duro censor, que ele faça o que não é dele, isto é, o nada; mas eis que o evangelista testemunha contra ti, dizendo que "o nada foi feito sem ele". Deus até aqui não aprendeu a fazer o nada. Ensine-o, tu, e instrua-o por ti que faça o nada. ${ }^{10}$

Como se vê, o próprio Pedro Damião se vale do princípio de não-contradição para defender que Deus não pode modificar o que foi feito. Essa passagem também mostra que a "incapacidade" divina de modificar o que já foi feito não contradiz sua onipotência, pois criar uma contradição não é propriamente uma potência, mas uma impotência (608D). Além disso, há uma outra razão para a inexistência de algo contraditório: a vontade de Deus. "A vontade do Criador supremo e onipotente é para todas as coisas a causa

\footnotetext{
10 "Tu itaque, dum quaeris unam eamdem rem et fuisse et non fuisse, esse et non esse, futuram esse et futuram non esse, niteris profecto quaeque facta uel facienda confundere, et inter esse uel non esse nutantia demonstrare. Quod certe rerum natura non habet. Nichil enim simul potest esse et non esse. Sed quod in rerum natura non est, procul dubio nichil est. Quaeris ergo a Deo, durus exactor, ut faciat quod suum non est, hoc est nichil. Sed ecce euangelista contra te stat dicens quia sine ipso factum est nichil. Deus adhuc non didicit facere nichil. Tu eum doce et praecipe ut tibi faciat nichil”. De divina omnipotentia, 608C.
} 
tão eficaz de sua existência ou de sua inexistência que o que ele quer que seja não pode não ser, e o que ele não quer que seja não tem nenhum meio de ser" (608D-610B). Por fim, é preciso observar que a ambiguidade entre ser e não ser simultaneamente não é coadunável com a natureza das coisas (610B-C).

Após essa exposição sobre as coisas boas, Damião retoma a discussão sobre a consequência da necessidade. Tratase de sua análise final, momento em que finalmente chegaremos ao trecho 612A-B. A necessidade que se segue de proposições verdadeiras é vista como resultado da vontade divina, causa eficiente de ser. A consequência da necessidade é um indicativo do poder da vontade de Deus, pois "se tudo o que é, é por ele, ele conferiu às coisas um poder de existir de tal natureza que uma vez que existiram, não podem não ter existido" (609A).

Até o momento, pelo que vimos, Damião parece defender a validade do princípio de não-contradição. ${ }^{11}$ Como observa Holopainen (1996, 34), o princípio de nãocontradição e a consequência da necessidade estão relacionados, pois ambos "estão estabelecidos na imutável presença de todos os fatos na providência de Deus e na eficiência do poder de Deus para produzir ser". Fazendo uso

\footnotetext{
${ }^{11}$ É preciso observar, no entanto, que a interpretação de Damião do princípio é um pouco diferente da habitual. Pois quando ele diz que algo não pode ser (esse) e não ser (non esse) ao mesmo tempo, o verbo esse se refere ao modo de ser das coisas boas. Desse modo, o princípio de nãocontradição é válido para as coisas más porque elas não têm ser nesse sentido. O que abre caminho, segundo Resnick (1992, 110-111), para seja possível a ocorrência de eventos contraditórios que não se enquadrem no padrão de Damião. Por exemplo, Deus poderia remover um evento mau do passado, e isso não contaria como uma contradição, pois o evento mau nem mesmo tem ser. Todavia, como nota Holopainen $(1996,34)$, não há em De divina omnipotentia qualquer indício dessa linha de raciocínio. De qualquer modo, esse raciocínio não se aplica à perda da virgindade, pois mesmo que a perda da virgindade não tenha ser, a virgindade tem, de modo que a remoção da perda implicaria que a virgindade é e não é simultaneamente, o que seria uma contradição mesmo para Damião.
} 
das palavras de Gonsette (1956, 95), "o valor absoluto do princípio de contradição, longe de ser um limite, representa, ao contrário, uma condição e a consequência necessária da onipotência de Deus".

Com efeito, o que foi não pode verdadeiramente ser dito que não foi, e, inversamente, o que não foi não é correto dizer que foi. Pois os contrários são incompatíveis em um e o mesmo sujeito. Esta impossibilidade, tem-se sem dúvida razão de afirmá-la quando é referida às limitações da natureza, mas não deve ser aplicada à majestade divina. Pois aquele que deu nascimento à natureza facilmente remove a necessidade da natureza quando ele quer.

O trecho 612A-B se insere numa passagem em que Damião defende que Deus tem o poder para mudar as leis da natureza. Ele começa tratando de determinados silogismos dos dialéticos (610D), e finaliza com a afirmação de que Deus pode restaurar a virgindade a uma mulher por meio de um milagre (614C), e a consequência da necessidade não limita o poder de Deus para produzir qualquer efeito, mesmo que contrário às leis da natureza (615B).

Ainda que os comentadores divirjam em suas análises a respeito do excerto $612 \mathrm{~A}-\mathrm{B}$, a maior parte parece assumir que a impossibilidade que Damião diz se aplicar à natureza e não a Deus é a impossibilidade de criar uma contradição. Tomemos esse pressuposto como nosso ponto de partida.

Apresentemos uma vez mais a objeção que nos coloca esta questão supérflua, e vejamos de qual raiz ela sai, a fim de que ela não venha a inundar e levar impetuosamente as ricas colheitas da fé sincera, mas que este riacho, digno de ser engolido pela terra, se torne seco com sua própria fonte. Pois à afirmação que Deus não pode reparar a virgindade após sua queda, acrescentam como por um encadeamento lógico (quasi consequenter): com efeito, Deus pode fazer que o que 
aconteceu não tenha acontecido? ${ }^{12}$

Pelo que diz Damião, o objetivo da passagem 612A-B é tratar da relação entre a restauração da virgindade e a modificação do passado, chamada de superstitiosa quaestio. Ele pretende mostrar que a questão está viciada, pois ela se origina do problema da restauração da virgindade. Ao que parece, alguns formulavam: Deus não pode fazer que o que é, não tenha sido; portanto, ele não pode restaurar a virgindade a uma mulher. $\mathrm{O}$ problema desse argumento (quasi consequenter) é que, como Damião procura mostrar, a restauração da virgindade não exige alteração do passado.

Como se, uma vez estabelecido que uma virgem foi deflorada, fosse impossível que ela reencontrasse sua integridade. Pela natureza, certamente, isso é verdadeiro, a proposição mantém: que algo ao mesmo tempo tenha sido e não tenha sido, não se pode identificar aí uma só e mesma coisa; com efeito, são duas coisas contrárias uma à outra, de modo que, se uma é verdadeira, a outra não pode sê-lo. E, com efeito, o que foi, não é verdadeiro dizer que isso não foi, e inversamente, o que não foi, não é correto dizer que isso foi; pois os contrários são incompatíveis em um e o mesmo sujeito. ${ }^{13}$

Damião sustenta que o modo de argumentar de seus interlocutores pode demonstrar que a virgindade não pode ser restaurada no que diz respeito à natureza. Isto é, assumindo-se que alguém perdeu a virgindade, é impossível que

\footnotetext{
12 "Proponatur adhuc superstitiosae quaestionis obloquium; uideatur etiam ex qua sit radice productum, quatinus, ne praecipiti raptu uberes sincerae fidei fruges obruat, hiatu terrae dignus cum ipso suo fonte riuus arescat. Ad adfirmandum namque quod Deus nequeat uirginem reparare post lapsum, quasi consequenter adiciunt: numquid enim potest Deus agere ut quod factum est factum non fuerit?". De divina omnipotentia, 611D-612A.

13 "Tamquam si semel constet ut fuerit uirgo corrupta, iam nequeat fieri ut rursus sit integra. Quod certe quantum ad naturam uerum est statque sententia. Factum quoque aliquid fuisse et factum non fuisse unum idemque inueniri non potest. Contraria quippe inuicem sunt adeo ut si unum sit, alterum esse non possit. Nam quod fuit non potest uere dici quia non fuit, et e diuerso quod non fuit non recte dicitur quia fuit. Quae enim contraria sunt in uno eodemque subiecto congruere nequeunt". De divina omnipotentia, 612A.
} 
ela volte a ser virgem depois disso, pois, considerando o curso ordinário da natureza, uma relação sexual remove definitivamente a integridade da carne. Dessa maneira, o único modo de uma mulher deflorada se tornar virgem novamente por meio da natureza é alterando o passado, de modo que ela nunca tenha se deitado com um homem. Entretanto, isso implicaria na violação do princípio de nãocontradição. Portanto, assim como não é possível desfazer o passado, também não é possível ter a virgindade restaurada pela natureza. ${ }^{14}$

Esta impossibilidade (haec inpossibilitas), tem-se sem dúvida razão de afirmá-la quando é referida às limitações (inopia) da natureza, mas não deve ser aplicada à majestade divina. Pois aquele que deu nascimento à natureza facilmente remove a necessidade da natureza quando ele quer. ${ }^{15}$

Considerando o passo anterior, haec inpossibilitas só pode se referir à natureza, que é incapaz de restaurar a virgindade. Não decorre disso que Deus também não possa fazê-lo, pois ele tem poder soberano sobre as leis da natureza. Haec inpossibilitas não diz respeito à incapacidade divina para restaurar a virgindade, decorrente da impossibilidade de se alterar o passado. "A impossibilidade não se aplica a Deus, não pela razão que Deus não poderia desfazer o feito (o que ele não pode), mas pela razão que Deus pode restaurar a virgindade através de um milagre em algum momento presente do tempo" (HOLOPAINEN 1996, 38). Esse é o tom da conclusão da discussão sobre o poder de Deus para

\footnotetext{
${ }^{14}$ Holopainen (1996, 38, nota 95) parece estar correto ao dizer que parte da confusão a respeito do trecho 612A-B se deve ao fato de Damião não ter deixado explícito esse momento de sua argumentação.

15 "Haec porro inpossibilitas recte quidem dicitur si ad naturae referatur inopiam; absit autem ut ad maiestatem sit applicanda diuinam. Qui enim naturae dedit originem, facile, cum uult, naturae tollit necessitatem". De divina omnipotentia, $612 \mathrm{~A}-\mathrm{B}$.
} 
mudar as leis da natureza (614C).

Desse modo, pode-se dizer que o objetivo de Pedro Damião em De divina omnipotentia 612A-B é mostrar que duas são as questões, e elas podem ser tratadas independentemente. $\mathrm{O}$ passado não pode ser desfeito, dado o poder da vontade de Deus como causa eficiente do ser dos seres. Todavia, a virgindade pode ser restaurada, pois as leis da natureza obedecem à sua vontade. Feito isso, Damião pode dizer o que acredita ser a atitude de fé esperada. Após mostrar que Deus não pode alterar o passado, ele parece interessado em destacar que isso não dá motivos para se atribuir a Deus qualquer tipo de impotência (618B-C).

Damião ainda dedica mais alguns parágrafos à discussão sobre a alteração do passado (619A-620C). Nessa nova análise, a imutabilidade e eternidade divinas serão o ponto de partida. Ele argumenta que há um sentido em que é possível dizer (non inepte) que Deus pode (potest) fazer com que aquilo que é, não tenha sido (619A). Visto que o poder de Deus (posse) é coeterno ao próprio Deus, ambos são igualmente imutáveis. Desse modo, assim como no início do tempo era possível que Deus não tivesse criado aquilo que hoje conhecemos como passado, ainda hoje (e para sempre) essa possibilidade está disponível para Deus (620A-B).

Ainda que se admita que essa discussão final não representa a posição principal de Damião sobre a questão, que se conceda ser essa "uma consideração adicional que pode ser usada para combater aquelas pessoas impudentes que não estão satisfeitas com essa solução principal" (HOLOPAINEN 1996, 41; PEDRO DAMIÃO 2006, 132. 133), é difícil não ver os problemas que ela suscita. Pois se é verdade que Deus não pode alterar o passado, como foi defendido na maior parte de De divina omnipotentia, é preciso 
que haja algo errado em qualquer argumento que diga o contrário.

Damião dirá se tratar de uma consideração de natureza gramatical. Em outras palavras, no caso da alteração do passado, quando dizemos que "Deus pode (potest) fazer X", na verdade deveríamos usar a expressão "Deus poderia (potuit) ter feito X", pois é a formulação adequada do nosso ponto de vista temporal. O tempo presente é apropriado somente quando diz respeito ao Deus eterno (619A-C). Dessa maneira, a afirmação "Deus pode desfazer o que já foi feito" deveria ser lida como "Deus poderia ter feito de um modo diferente do que é hoje".

Por fim, apesar da estranheza de sua última consideração, a obra De divina omnipotentia pode ser lida como um todo coerente. Damião defende que Deus pode restaurar a integridade da carne, e isso não implica na alteração do passado. Trata-se de um milagre, resultado do poder divino sobre as leis da natureza. A validade do princípio de nãocontradição não é posta em xeque, pois Deus não pode desfazer aquilo já feito. Contudo, isso não significa que ele seja impotente em qualquer sentido, pois essa "restrição" é resultado de seu poder soberano. A passagem 612A-B, como vimos, pode ser lida como uma afirmação da validade universal do princípio de não-contradição.

Desse modo, o que se pode dizer da atitude de Pedro Damião em relação à dialética? Ele não ataca a validade do princípio de não-contradição, assim como não chega a elaborar uma crítica geral aos princípios dialéticos, mas também não parece um entusiasta da mesma, sobretudo em questões de fé. Sua consideração final sobre a possibilidade de alteração do passado, destinada àqueles que teimam em assumir que Deus pode fazê-lo, parece indicar um certo des- 
leixo em relação à dialética. Uma posição um tanto sofística. Algo bem diferente da visão de Anselmo, que, sola ratione, buscará intelligere alguma coisa dos assuntos da fé. Dessa maneira, por não desejar aplicar a dialética em teologia, Damião poderia ser caracterizado como uma espécie de antidialético moderado.

Abstract: Peter Damian (1007-1072) is usually described in the History of Philosophy as a kind of enemy of dialectic, the major example of the medieval anti-intelectual. Much of his fame is the result of an excerpt from his work De divina omnipotentia, in which he seems to argue that God could break the principle of non-contradiction. In this paper, we intend to show that Damian does not attack the validity of the principle of noncontradiction, and does not build a general critique of the dialectical principles. However, he also does not seem enthusiastic about it, especially in matters of faith. So although it is not fair to characterize him as an obstinate anti-intellectual, it is necessary to consider his little enthusiasm for the application of dialectic in theology.

Keywords: Peter Damian; dialectic; principle of non-contradiction.

\section{REFERÊNCIAS}

ANSELMO DE CANTUÁRIA. Opera omnia: ad fidem codicum recensuit. Franciscus Salesius Schmitt. Stuttgart: Frommann, [1946-1961] 1984. 2 vols.

BARBOSA FILHO, B. Aristóteles e o princípio de bivalência. Analytica, vol. 9, no 1, 2005, p. 173-184.

- Nota sobre o conceito aristotélico de verdade. Cadernos de História e Filosofia da Ciência, série 3, vol. 13, no 2, 2003, p. 233-242.

BOEHNER, Ph.; GILSON, É. História da filosofia cristã: desde as origens até Nicolau de Cusa. Petrópolis: Vozes, 2000.

BOÉCIO. De hypotheticis syllogismis. Edição de L. Orbetel- 
lo. Brescia: Paideia,1969.

. Commentarii in librum Aristotelis Peri Hermeneias. Edição de Carolus Meiser. Leipzig: 1880. 2 vols.

CÍCERO. De inventione. Edição de G. Friedrich (M. Tulli Ciceronis scripta quae manserunt omnia 1.1). Leipzig: Teubner, 1908.

COURTENAY, W. J. The dialectic of omnipotence in the high and late Middle Ages. In: RUDAVSKY, T. (ed.). Divine omniscience and omnipotence in Medieval Philosophy. Synthese Historical Library, 25. Dordrecht: Reidel, 1985, p. 243-269.

ENDRES, J. A. Die Dialektiker und ihre Gegner im 11. Jahrhundert. Philosophisches Jahrbuch, 19, 1906, p. 20-33.

GONSETTE, J. A. D. Pierre Damien et la culture profane. Louvain: Publications Universitaires de Louvain, 1956.

HOLOPAINEN, T. J. Dialectic and theology in the eleventh century. Leiden: Brill, 1996.

MÁRIO VITORINO. Explanationes in Ciceronis rhetoricam. Edição de J. C. Orelli (M. Tulli Ciceronis Opera 5.1). Zurich : Fuesslini, 1833.

PEDRO DAMIÃO. Opera omnia. Patrologia Latina, 144145. Turnhout: Brepols, [1853] 1994-1995. 2 vols.

. Lettre sur la toute-puissance Divine. Introdução, texto crítico, tradução e notas por A. Cantin. Sources Chrétiennes, 191. Paris: Cerf/CNRS, 2006.

RESNICK, I. M. Divine power and possibility in St. Peter 